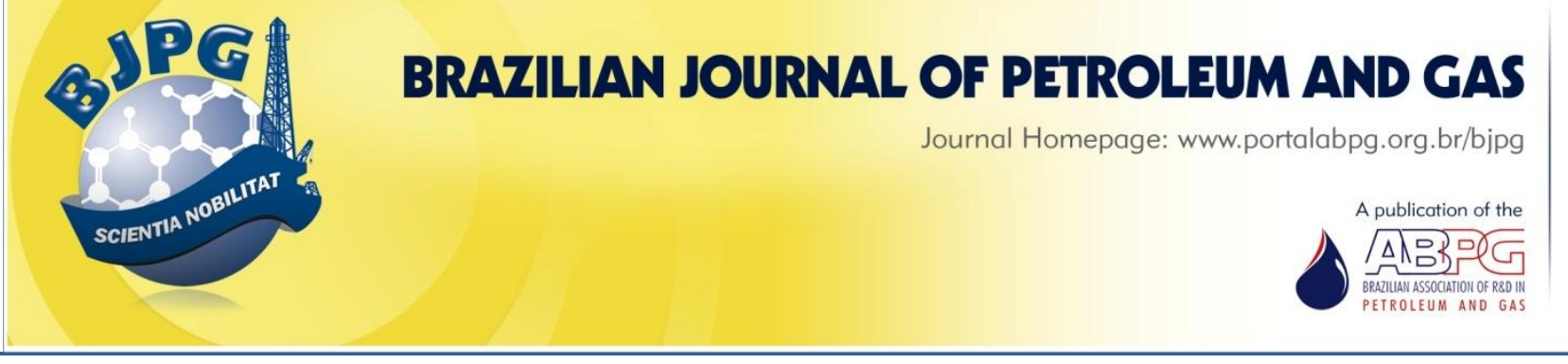

\title{
PHENOL ESTIMATION USING FLORY-HUGGINS PARAMETERS AND CLOUD POINT OF POLIETHOXYLATE SURFACTANTS
}

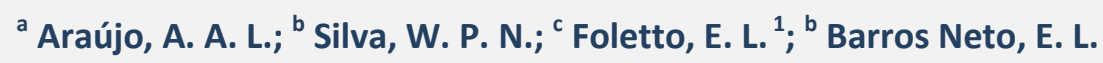 \\ ${ }^{a}$ Federal Rural University of the Semi-arid Region- UFERSA, Mossoró - RN - Brazil \\ ${ }^{b}$ Federal University of Rio Grande do Norte, Department of Chemical Engineering, Natal - RN - Brazil \\ ${ }^{\mathrm{C}}$ Federal University of Santa Maria, Department of Chemical Engineering, Santa Maria - RS - Brazil \\ Received: 16.10.2018 / Revised: 21.01.2019 / Accepted: 30.01.2019 / Published on line: 03.04.2019
}

\begin{abstract}
This work examines the thermodynamics of phenol extraction by cloud point varying the ethoxylation degrees of nonylphenolpoliethoxylate surfactants (NPEOn) $(9.5,10,11$ and 12). The Flory-Huggins model was applied to estimate enthalpy $\left(\Delta \mathrm{H}_{\text {mix }}\right)$ and entropy $\left(\Delta \mathrm{S}_{\text {mix }}\right)$ parameters of the mixture, as well as the aggregate number $(N)$. Results show that $\Delta \mathrm{H}_{\text {mix }}$ and $\Delta \mathrm{S}_{\text {mix }}$ values have a direct relationship with the ethoxylation degree of the surfactant used. Differently, aggregate number $(N)$ values have an inverse relationship with the ethoxylation degree. The fitting to the Flory-Huggins model presented a standard deviation $(S D)$ that ranged from 0.161 to 4.037 for each surfactant studied. It was observed that the increase of the phenol concentration in the surfactant + water system resulted in a decrease in the cloud point of the studied surfactants. These results contribute significantly to the application of this type of surfactant in phenol extraction processes.
\end{abstract}

\section{KEYWORDS}

non-ionic surfactant; cloud point; phenol; Flory-Huggins model

\footnotetext{
${ }^{1}$ To whom all correspondence should be addressed.

Address: Federal University of Santa Maria, Department of Chemical Engineering, Santa Maria - RS, Brazil.

ZIP Code: 97105-900 | e-mail: efoletto@gmail.com

doi:10.5419/bjpg2019-0002
} 


\section{INTRODUCTION}

The application of non-ionic surfactants in the process of solute extraction from aqueous mediums has been increasing over time, implying the need for knowledge of thermodynamic properties, cloud point, or critical point of these surfactants (Inoue et al., 2008; Watanabe \& Tanaka, 1978; Clark \& Lipson, 2012; Stephen et al., 1992). One of the characteristics of the cloud point is the formation of a coacervate phase, which is extractant and has been used widely to replace organic solvents, usually toxics, in more efficient extraction, separation, or purification methods of various organic compounds or metallic ions (Gu \& Galera-Gomez, 1992; Kulek et al. 2017; Yang et al., 2017ab).

Based on this idea, the present work studies the influence of phenol on the cloud point of poliethoxylates surfactants. Phenol is employed largely in the industry for the production of plastics, pesticides, resins, and medicines (Hou et al., 2017; Wang et al., 2017; Li et al. 2017; Delgado-Marín, 2017). Therefore, it is important to study the effects of phenol on the cloud point of non-ionic surfactants. This study will allow us to predict phase separation temperature of non-ionic surfactants in phenol extraction.

Some studies use the cloud point for extraction or purification, for example, phorbol was recovered using a cloud point extraction technique described by Phasukarratchai et al. (2017); dyes were removed by a non-ionic surfactant using the cloud point extraction technique (Melo et al., 2014; Appusamy et al., 2014); amino acids were extracted using triton x-100 (Volodymyr \& Oksana, 2017), bisphenol was extracted from water using a cationic surfactant at its cloud point (Yi-Jun et al., 2009); and $\mathrm{Cu}^{2+}$ was extracted using a mixture of Tritox100 and dithizone (Sato et al., 2013). Mixtures of non-ionic surfactants such as Triton X114/Triton X100 have been employed in the cloud point extraction (Nazar et al., 2011). Therefore, it is important to study the temperature of the cloud point of these substances to determine the phase separation point and promote the extraction.

Several published works report the influence of additives in the cloud point, such as salts, hydroxides, or even the mixture of surfactants, aiming to estimate and control the temperature of the phase separation. Some examples found in literature are: the effect of electrolytes on Triton X114 cloud point (Santos-Ebinuma et al., 2013); the influence of chaotropic anions on the cloud point of octoxynol 9 surfactant (Triton X-100) (Schott, 1997); as well as the presence of salts decreasing the cloud point of surfactant TX-405 (Akbas \& Batigoc, 2009). Other works report thermodynamic studies, such as the determination of enthalpy, entropy, and Gibbs free energy of solutions containing surfactants in processes that involve dyes extraction by cloud point (Purkait et. al., 2009; Tang et al., 2017). The influence of electrolytes on enthalpy, entropy, and Gibbs free energy in solutions containing non-ionic surfactants was also studied (Batıgöç \& Akbaş, 2017), and the effect of salts in mixtures containing Triton x114/Gemini $16-616$ on determining the enthalpy, entropy, and Gibbs free energy of these systems (Shivaji et al., 2003).

This work determined, experimentally, the cloud points of nonylphenolpoliethoxylates nonionic surfactants in the presence of the phenol with the goal of verifying its influence on cloud point. The Levenberg-Marquardt method was applied to estimate cloud point parameters for the surfactants using the Flory-Huggins model. This model is capable of foreseeing the cloud point of these surfactants in the presence of phenol. A minimization routine was developed in Scilab ${ }^{\circledR}$ to estimate Flory-Huggins parameters such as heat of mixing $\left(\Delta \mathrm{H}_{\text {mix }}\right)$, entropy of mixing $\left(\Delta \mathrm{S}_{\text {mix }}\right)$, and the aggregation numbers of surfactants $(N)$.

\section{METHODOLOGY}

\subsection{Materials}

Type NPEOn surfactants containing different ethoxylation degrees $(n): 9.5 ; 10 ; 11$; and 12 were used in this work. These surfactants were provided by OXITENO (São Paulo, Brazil). Other reagents used had an analytical degree. Deionized purified water was used to prepare the solutions. A phenol from VETEC was used in concentrations that ranged from 0.01 to $0.25 \%$ in mass. 


\subsection{Experimental procedure}

The cloud point was obtained through solutions containing surfactant and phenol. Surfactant concentrations varied between 0.5 and $25 \%$ (by mass), and the phenol concentrations varied from 0.01 to $0.25 \%$ (by mass). The solutions were allocated into $100 \mathrm{~mL}$ beakers and placed in a thermostatic bath (Water Separability Tester; Koehler Instrument Company Inc., USA) under constant stirring at $300 \mathrm{rpm}$. Bath temperature was gradually increased at a rate of $1^{\circ} \mathrm{C} / \mathrm{min}$ until the solution was cloudy to the eye. In addition, a thermocouple (Salvterm 700K-SALCAS) $\pm 0.1^{\circ} \mathrm{C}$ was inserted into the solution to determine the cloud point temperature. The cloud point was established through the average temperature during the heating process, followed by the cooling of the solution in triplicate (Wang et al., 2008). The data treatment applied to the Flory-Huggins model was carried out in a routine developed in the Scilab 5.4.1 ${ }^{\circledR}$ platform.

\subsection{Acquisition of cloud point parameters}

\subsubsection{Flory-Huggins model}

The Flory-Huggins model is used commonly in polymeric solutions (Saeki, 1997), since it is based on the chemical potential of the involved phases (Eq. 1) (Inoue et al., 2003). Equations 1 to 4 estimate the enthalpy and entropy mixture parameters, as well as the aggregation number of molecules in the micelle, represented by $\Delta \mathrm{H}_{\text {mix }}$ $\Delta \mathrm{S}_{\text {mix }}$ and $N$, respectively.

$\mu_{1}^{m}-\mu_{1}^{d}=\frac{\partial \Delta G_{m}}{\partial n_{1}}$

Where $\mu_{1}^{m}$ and $\mu_{1}^{d}$ are the chemical potential of the most concentrated and diluted phase in relation to component $1, \Delta G_{m}$ is the Gibbs free energy of the mixture, and $n_{1}$ is the number of moles of component 1 . Eq. 2 estimated the chemical potential of the most concentrated phase.

$\mu_{1}^{m}=\mu_{1}^{d}+\frac{R T}{\beta}\left[\ln \left(1-\phi_{m}\right)+\left(1-\frac{1}{N}\right) \phi_{m}-\frac{\omega_{12}}{R T} \phi_{m}^{2}\right]$

Where $\omega_{12}$ is the interaction parameter between surfactant and water molecules represented by Eq. 3; 6 corresponds to the number of water molecules; and $\phi_{m}$ is the volumetric fraction of the solute.

$\omega_{12}=\Delta H_{m i x}-T \Delta S_{m i x}$

Replacing Eq. 3 in Eq. 2 generates Eq. 4.

$\frac{\partial \Delta G_{m}}{\partial n_{1}}=\frac{R T}{\beta}\left[\ln \left(1-\phi_{m}\right)+\left(1-\frac{1}{N}\right) \phi_{m}-\frac{\Delta H_{m i} \phi_{m}^{2}}{R T}+\frac{\Delta S_{m i x} \phi_{m}^{2}}{R}\right]$

In equilibrium, the chemical potential for component 1 in the diluted phase is equal to the chemical potential in the most concentrated phase, $\mu_{1}^{d}=\mu_{1}^{m}$. Therefore, since the chemical potential is constant, the derivative of Gibbs free energy is zero, resulting in Eq. 5 .

$$
T_{i}^{c a l c}=\frac{\Delta H_{m i x} \phi_{m}^{2}}{R\left[\ln \left(1-\phi_{m}\right)+\left(1-\frac{1}{N}\right) \phi_{m}\right]+\Delta S_{m i x} \phi_{m}^{2}}
$$

Where $T_{i}^{\text {Calc }}$ corresponds to the temperature of the estimated cloud point, according to the FloryHuggins model; and $\Delta H_{\text {mix }}, \Delta S_{\text {mix }}$, and $N$ are the thermodynamic parameters, respectively. These parameters were estimated for each system using a minimization routine of the LevenbergMarquardt numerical method. Thus, Eq. 5 represents the model used for the estimation of cloud point parameters. Eq. 6 displays the representation of the objective function used for calculating the minimization.

$$
F . O=\sum_{i=1}^{n}\left(\frac{T_{i}^{\text {exp }}-T_{i}^{\text {calc }}}{n}\right)^{2}
$$

Where $T_{i}^{\text {exp }}$ represents the temperatures obtained from the experiments, and $n$ is the data number.

\section{RESULTS E DISCUSSION}

Phenol extraction by cloud point, including the thermodynamic study, has been the object of previous works (Neves Silva et al., 2015; Sayem \& Mandal, 2015). Results show that ethoxylation degree, surfactant concentration, and phenol concentration affect significantly the process. Figure 1 shows the construction of the FloryHuggins model curves by predicting the turbidity point curves, along with the experimental data. 

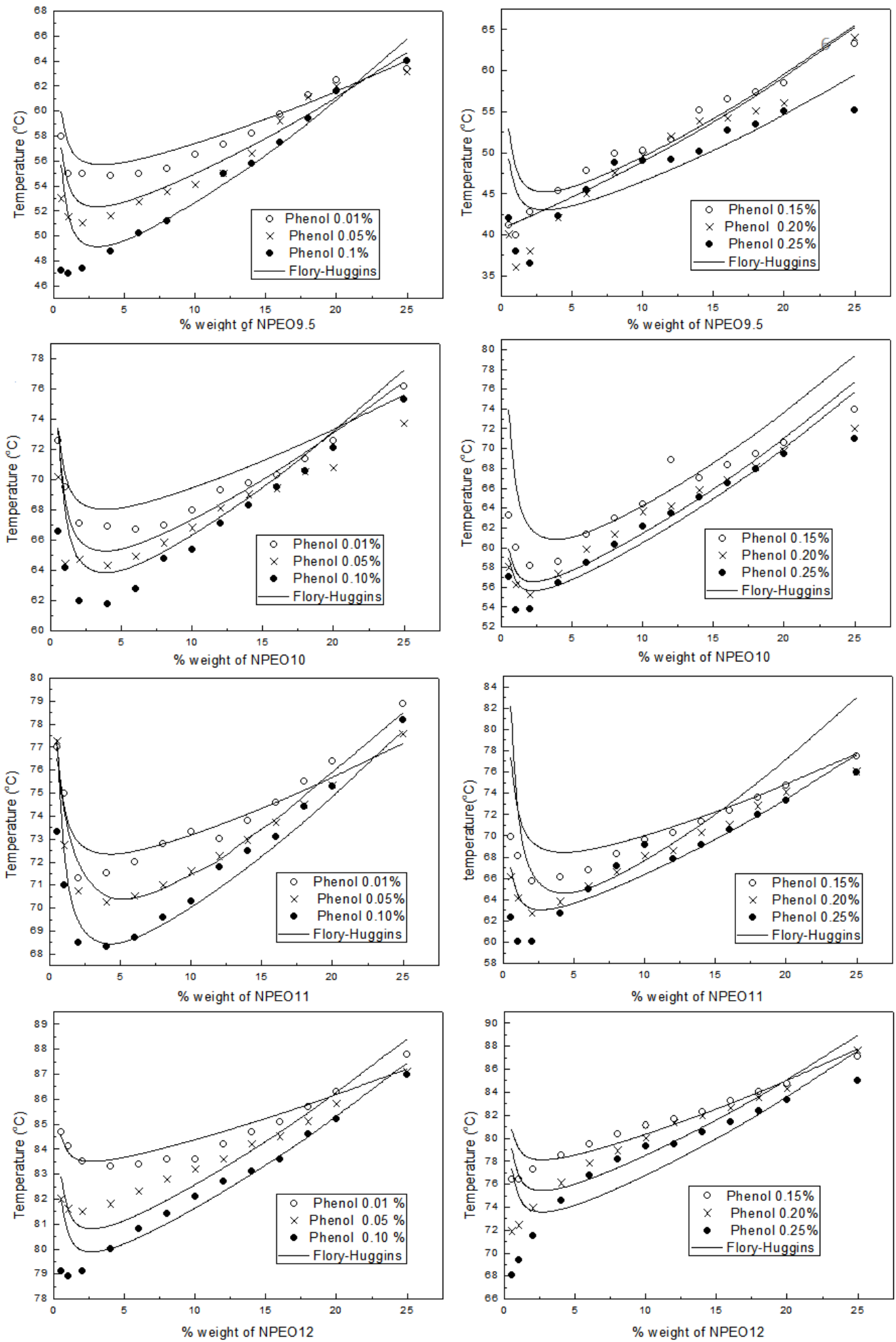

Figure 1. Experimental cloud point data for NPEO 9.5, NPEO10, NPEO11, and NPEO12; and adjustment by FloryHuggins model.

Figure 1 shows the cloud point, also called critical point of phase separation. It is calculated according to the surfactant concentration. The temperature of the cloud point increases with the increase of the ethoxylation degree for both surfactants (Inoue \& Yasutaka, 2010). This can be associated to the greater affinity of the surfactant of the highest ethoxylation degree with water. Therefore, more energy is needed to break these bonds and, consequently, the cloud temperature increases (Zana \& Weill, 1985). 
Table 1. Parameters of Flory-Huggins model with phenol.

\begin{tabular}{cccccccc}
\hline & Phenol $(\mathrm{m} / \mathrm{m} \%)$ & $0.01 \%$ & $0.05 \%$ & $0.10 \%$ & $0.15 \%$ & $0.20 \%$ & $0.25 \%$ \\
\hline \multirow{4}{*}{ NPEO9.5 } & $\Delta \mathrm{H}_{\text {mix }}(\mathrm{kJ} / \mathrm{mol})$ & 9.094 & 6.201 & 4.555 & 3.693 & 3.223 & 4.460 \\
& $\Delta \mathrm{S}_{\text {mix }}(\mathrm{J} / \mathrm{mol} . \mathrm{K})$ & 31.994 & 23.375 & 18.459 & 15.923 & 14.537 & 18.430 \\
& $N$ & 3900 & 3900 & 3900 & 3900 & 3900 & 3900 \\
& $S D$ & 0.959 & 1.082 & 1.332 & 1.637 & 4.037 & 3.311 \\
& $R^{2}$ & 0.9591 & 0.8050 & 0.9404 & 0.9113 & 0.7361 & 0.6638 \\
& $\Delta \mathrm{H}_{\text {mix }}(\mathrm{kJ} / \mathrm{mol})$ & 10.423 & 6.994 & 5.811 & 4.202 & 4.202 & 4.202 \\
& $\Delta \mathrm{S}_{\text {mix }}(\mathrm{J} / \mathrm{mol} . \mathrm{K})$ & 35.082 & 25.084 & 21.608 & 16.946 & 17.028 & 17.064 \\
& $N$ & 2500 & 2500 & 2500 & 2500 & 2500 & 2500 \\
& $S D$ & 1.136 & 1.532 & 2.434 & 3.962 & 1.775 & 1.835 \\
& $R^{2}$ & 0.8306 & 0.8206 & 0.7998 & 0.7893 & 0.8999 & 0.9029 \\
& $\Delta \mathrm{H}_{\text {mix }}(\mathrm{kJ} / \mathrm{mol})$ & 16.135 & 10.736 & 8.289 & 8.289 & 4.202 & 5.764 \\
& $\Delta \mathrm{S}_{\text {mix }}(\mathrm{J} / \mathrm{mol} . \mathrm{K})$ & 51.086 & 35.631 & 28.653 & 28.653 & 16.829 & 21.450 \\
& $N$ & 2000 & 2000 & 2000 & 2000 & 2000 & 2000 \\
& $S D$ & 0.773 & 0.586 & 1.219 & 2.591 & 3.015 & 2.158 \\
& $R^{2}$ & 0.9612 & 0.9541 & 0.8688 & 0.9515 & 0.8805 & 0.7903 \\
& $\Delta \mathrm{H}_{\text {mix }}(\mathrm{kJ} / \mathrm{mol})$ & 24.796 & 12.011 & 12.011 & 9.394 & 6.670 & 6.356 \\
& $\Delta \mathrm{S}_{\text {mix }}(\mathrm{J} / \mathrm{mol} . \mathrm{K})$ & 73.827 & 38.237 & 38.326 & 31.049 & 23.438 & 22.637 \\
& $N$ & 5000 & 5000 & 5000 & 5000 & 5000 & 5000 \\
& $S D$ & 0.161 & 1.962 & 0.949 & 1.457 & 2.497 & 3.337 \\
& $S D$ (standard deviation), $\Delta \mathrm{H}_{\text {mix }}$ (enthalpy of mixing), $\Delta \mathrm{S}_{\text {mix }}$ (entropy of mixing), $R^{2}$ (correlation coefficient)
\end{tabular}

Figure 1 also shows the effect of phenol concentration $\left(X_{f}\right)$ on the decrease of surfactant's cloud point (Duarte \& Canselier, 2005). There was a significant interaction between phenol and surfactant. This interaction suggests that the phenol interacts mainly with the surfactant's head, obtaining a less hydrophilic character (Naqvi et al., 2010).

Table 1 shows the values of the obtained parameters.

Positive $\Delta \mathrm{H}_{\text {mix }}$ values indicate that the surfactant solubilization in water is endothermic (Darshak et al., 2015; Badruzzaman et al., 2015). One can observe that there is a decrease in $\Delta \mathrm{H}_{\text {mix }}$ value and a corresponding increase in the phenol concentration for a fixed concentration of surfactant. This change is related to the decrease of the phenol solubility in the surfactant. Results also show an increase in $\Delta \mathrm{S}_{\text {mix }}$ value, related to an increase of the free surfactant chain in the diluted phase. On the other hand, the micellar concentration of the surfactant decreased with the increase in phenol concentration. This result leads to a reduction in the number of surfactant molecules in the diluted phase, causing a decrease in $\Delta S_{\text {mix }}$ value. Positive values of enthalpy and entropy were also reported in literature (Batıgocet al., 2011; Molina-Bolívar et al., 2013).

For the NPEO surfactant, one can observe that $\Delta \mathrm{H}_{\text {mix }}$ and $\Delta \mathrm{S}_{\text {mix }}$ increase with the increase in ethoxylation degree. Surfactants with a higher ethoxylation degree need greater energy (enthalpy) to break bonds formed with water. Molecules are more agitated when the amount of heat is increased during enthalpy, resulting in an increase of entropy. Surfactants with a higher ethoxylation degree have a larger polar region, and because of this increase in diameter of the polar part, fewer surfactant molecules will come together to form micellar aggregates (Boruah et al., 2010). The presence of the phenol causes a decrease in system enthalpy, a fact that is related directly to the interaction of the phenol with the surfactant's head group. In this case, the phenol will decrease the effect of the surfactant molecules solvation, causing the decrease of enthalpy and entropy. 


\section{CONCLUSIONS}

Results presented in this work show that phenol influences negatively the cloud point. This effect was triggered by interaction between phenol and the polar region of the surfactant. In addition, ethoxylation degree interferes positively in the temperature of the cloud point. The Flory-Huggins model adjusted satisfactorily to experimental data, showing positive enthalpy and entropy. Therefore, the presence of phenol caused a decrease in cloud point, while the ethoxylation degree of the surfactant caused an increase in the cloud point.

\section{REFERENCES}

Akbas, H.; Batigoc, C. Spectrometric studies on the cloud points of Triton X- 405. Fluid Phase Equilibria, v. 279, p. 115-119, 2009. https://doi.org/10.1016/j.fluid.2009.02.014

Appusamy, A.; Indulekha, J.; Ponnusamy, K.; Ramalingam A. Removal of crystal violet dye from aqueous solution using triton $\mathrm{X}-114$ surfactant via cloud point extraction. Journal of Engineering Science and Technology, v. 17, p. 137-144, 2014. https://doi.org/10.1016/j.jestch.2014.04.008

Badruzzaman, M. K.; Anamul, M. H.; Shafiqul, I. D. M. Physicochemical investigation of the clouding behavior and thermodynamics of p-tertalkylphenoxy poly (oxyethylene) ether micelles in aqueous environment and in the presence of diols. Journal Chemical Thermodynamics, v. 89, p. 177182, 2015.

https://doi.org/10.1016/i.jct.2015.05.008

Batıgöç, Ç.; Akbaş, H. Thermodynamic parameters of clouding phenomenon in nonionic surfactants: The effect of the electrolytes. Journal of Molecular Liquids, v. 231, p. 509-513, 2017. https://doi.org/10.1016/i.molliq.2017.02.024

Batıgoc, Ć.; Akbas, H.; Boz, M. Thermodynamics of non-ionic surfactant Triton X-100-cationic surfactants mixtures at the cloud point. The Journal of Chemical Thermodynamics, v. 43, p. 1800-1803, 2011.

https://doi.org/10.1016/i.jct.2011.06.005
Boruah, B.; Palash, M. S.; Gohain, B.; Dutta, R. K. Partition equilibrium of phenol red in aqueous polymer-surfactant system: Determination of critical aggregation concentration. Journal of Molecular Liquids, v. 151, p.81-85, 2010. https://doi.org/10.1016/i.molliq.2009.11.007

Clark, E. A.; Lipson, J. E. G. LCST and UCST behavior in polymer solutions and blends. Polymer, v. 53, p. 536-545, 2012.

https://doi.org/10.1016/i.polymer.2011.11.045

Darshak, R. B.; Kalpana, C. M.; Parikh J. Enhanced separation of toxic Blue BG dye by cloud point extraction with IL as an additive: Effect of parameters, solubilization isotherm and evaluation of thermodynamics and design parameters. Journal of Environmental Chemical Engineering, v.3, p. 1365-1371, 2015.

https://doi.org/10.1016/j.jece.2014.11.031

Delgado-Marín, L.; Sánchez-Borzone, M.; García, D. A. Neuroprotective effects of gabaergic phenols correlated with their pharmacological and antioxidant properties. Life Sciences, v. 175, p.1115, 2017. https://doi.org/10.1016/j.lfs.2017.03.005

Duarte, L. J. N; Canselier, J.P. Extração no ponto nuvem de compostos orgânicos homólogos e isômeros. Química Nova, Brasil, v. 3, p. 426-432, 2005. (in Portuguese) https://doi.org/10.1590/\$0100$\underline{40422005000300012}$

Gu, T.; Galera-Gomez, P. A. The effect of different alcohols and other polar organic additives on the cloud point of Triton X-100 in water. Colloids and Surfaces A: Physicochemical and Engineering Aspects, v. 147, p. 365-370, 1999. https://doi.org/10.1016/S0927-7757(98)00710-9

Hou, Y.; Kong, J.; Ren, Y.; Ren, S.; Wu, W. Mass transfer dynamics in the separation of phenol from model oil with quaternary ammonium salts via forming deep eutectic solvents. Separation and Purification Technology, v. 174, p. 554-560, 2017. https://doi.org/10.1016/i.seppur.2016.10.038

Inoue, T.; Higuchi, Y.; Misono, T. Differential scanning calorimetric study of nonionic surfactant mixtures with a room temperature ionic liquid, bmimBF4. Journal of Colloid and Interface Science, v. 338, p. 308-311, 2008.

https://doi.org/10.1016/i.jcis.2009.05.031 
Inoue, T.; Ohmura, H.; Murata, D. Cloud point temperature of polyoxyethylene-type nonionic. Colloid and Interface Science, v. 258, p. 374-382, 2003. https://doi.org/10.1016/S0021-9797(02)00162-5

Inoue, T.; Yasutaka, I. Cloud point phenomena of polyoxyethylene-type surfactants in ionic liquid mixtures of emimBF4 and hmimBF4. Journal of Colloid and Interface Science, v. 348, p. 522-528, 2010. https://doi.org/10.1016/j.jcis.2010.04.089

Kulek, A. J.; Kulek, C. A.; Felsner, M. L.; Pércio, S. Q.; dos Anjos, V. E. Pre-concentration and speciation of inorganic antimony in bottled water and natural water by cloud point extraction with Electrothermal Atomic Absorption Spectrometry. Microchemical Journal, v. 133, p. 222-230, 2017. https://doi.org/10.1016/i.microc.2017.03.043

Li, A.; Shen, K.; Chen, J.; Zhong, L.; Li, T. Highly selective hydrogenation of phenol to cyclohexanol over MOF-derived non-noble Co-Ni@NC catalysts. Chemical Engineering Science, v. 166, p. 66-76, 2017. https://doi.org/10.1016/i.ces.2017.03.027

Melo, R. P. F.; Barros Neto, E. L.; Moura, M. C. P. A.; Castro Dantas, T. N.; Dantas Neto, A. A.; Oliveira, H. N. M. B. Removal of Reactive Blue 19 using nonionic surfactant in cloud point extraction. Separation and Purification Technology, v. 138, p. 71-76, 2014.

https://doi.org/10.1016/j.seppur.2014.10.009

Molina-Bolívar, J. A.; Hierrezuelo, J. M.; Ruiz, C. Energetics of clouding and size effects in non-ionic surfactant mixtures: The influence of alkyl chain length and $\mathrm{NaCl}$ addition. Journal Chemical Thermodynamics, v. 57, p. 59-66, 2013.

https://doi.org/10.1016/j.jct.2012.08.002

Nazar, F. M.; Sakhawat, S. S.; Eastoe, J.; Khan, A. $M$; Shah, A. Separation and recycling of nanoparticles using cloud point extraction with non-ionic surfactant mixtures. Journal of Colloid and Interface Science, v. 63, p. 490-496, 2011. https://doi.org/10.1016/i.jcis.2011.07.070

Naqvi, A. Z.; Al-Ahmadi, M. D. A.; Akram, M.; Kabir-ud-Din. Surfactants and ureas affect the cloud point of amphiphilic drug, clomipramine hydrochloride. Colloids and Surfaces B: Biointerfaces, v. 81, p. 152-157, 2010.

https://doi.org/10.1016/i.colsurfb.2010.07.003
Neves Silva, W. P. N.; Nascimento, A. E. G.; Moura, M. C. P. A.; de Oliveira, H. N. M.; Barros Neto, E. L. Study of phenol removal by cloud point extraction: A process optimization using experimental design. Separation and Purification Technology, v. 152, p.133-139, 2015. https://doi.org/10.1016/i.seppur.2015.08.007

Phasukarratchai, N.; Damrongsiri, S.; Tongcumpou, C. Recovery of phorbol esters from pressed jatropha seeds by surfactant extraction and cloud-point separation. Industrial Crops and Products, v. 95. p. 549-557, 2017.

https://doi.org/10.1016/j.indcrop.2016.11.009

Purkait, M. K.; Das Gupta, S.; Deb, S. Determination of thermodynamic parameters for the cloud point extraction of different dyes using TX-100 and TX-114. Desalination, v. 244, p. 130 138, 2009. https://doi.org/10.1016/j.desal.2008.04.042

Saeki, S. Calculation of combinatory entropy in complex polymer solutions based on the FloryHuggins theory. Fluid Phase Equilibria, v. 136, p. 79-85, 1997. https://doi.org/10.1016/S0378$\underline{\text { 3812(97)00111-8 }}$

Santos-Ebinuma, V. C.; Lopes, A. M.; Converti, A.; Pessoa Júnior, A.; Rangel-Yagui, C. O. Behavior of Triton X-114 cloud point in the presence of inorganic electrolytes. Fluid Phase Equilibria, v. 360, p. 435-438, 2013.

https://doi.org/10.1016/j.fluid.2013.09.053

Sato, N.; Morin, M.; Itabashi, H. Cloud point extraction of $\mathrm{Cu}(\mathrm{II})$ using a mixture of triton X-100 and dithizone with a salting-out effect and its application to visual determination. Talanta, v. 117, p. 376-381, 2013.

https://doi.org/10.1016/j.talanta.2013.08.025

Sayem, M. A.; Mandal, A. B. The clouding phenomena of mixed surfactant (non-ionic Triton $\mathrm{X}-114+$ cationic gemini $16-5-16)$ solutions: Influence of inorganic and organic additives on the cloud point. Journal of Molecular Liquids, v. 212, p. 237-244, 2015.

https://doi.org/10.1016/i.molliq.2015.08.051

Schott, H. Effect of Inorganic Additives on Solutions of Nonionic Surfactants - XIV. Effect of Chaotropic Anions on the Cloud Point of Octoxynol 9 (Triton X-100). Journal of Colloid and Interface Science, v. 189, p. 117- 122, 1997.

https://doi.org/10.1006/icis.1997.4822 
Shivaji, S. K.; Sandeep, R. P.; Rakshit, A. K. Study of the cloud point of C12En nonionic surfactants: Effect of additives. Colloids and Surfaces A: Physicochem. Eng. Aspects, v. 219, p. 67-74, 2003. https://doi.org/10.1016/S0927-7757(03)00012-8

Stephen, J. M.; Qian, C.; Eichinger, B. E. Phase diagrams of quasi-binary polymer systems with LCST/UCST spinodals and hour-glass cloud-point curves. Polymer, v. 33, p. 5105-5108, 1992. https://doi.org/10.1016/0032-3861(92)90068-8

Tang, X.; Zhu, D.; Huai, W.; Zhang, W.; Fu, C.; Xie, C.; Quan, S.; Fan, H. Simultaneous extraction and separation of flavonoids and alkaloids from Crotalaria sessiliflora L. by microwave-assisted cloud-point extraction. Separation and Purification Technology, v. 175, p. 266-273, 2017. https://doi.org/10.1016/i.seppur.2016.11.038

Volodymyr, O. D.; Oksana, G. M. The peculiarities of the interphase distribution of amino acids in the cloud point extraction systems. Colloids and Surfaces A: Physicochem. Eng. Aspects, v. 520, p.757-763, 2017. https://doi.org/10.1016/j.colsurfa.2017.02.036

Wang, Z.; Dang, D.; Lin, W.; Song, W. Catalytic pyrolysis of corn straw fermentation residue for producing alkyl phenols. Renewable Energy, v. 109, p. 287-294, 2017.

https://doi.org/10.1016/i.renene.2017.03.060

Wang, G. Z.; Xu, J.; Zhang, W.; Baohua, Z. Q. H. Cloud point of nonionic surfactant Triton X-45 in aqueous solution. Colloids and Surfaces B: Biointerfaces, v. 61 p. 118-122, 2008. https://doi.org/10.1016/j.colsurfb.2007.07.013
Watanabe, H.; Tanaka, H., A non-ionic surfactant as a new solvent for liquid-liquid extraction of zinco(II) with I-(2-pyridylazo)-2naphthol. Talanta, v. 25, p. 585-589, 1978. https://doi.org/10.1016/0039-9140(78)80151-9

Yang, X.; Jia, Z.; Yang, X.; Gu, L., Liao, X. Cloud point extraction-flame atomic absorption spectrometry for pre-concentration and determination of trace amounts of silver ions in water samples. Saudi Journal of Biological Sciences, v. 24, p. 589-594, 2017a.

https://doi.org/10.1016/j.sjbs.2017.01.030

Yang, Y.; Reed, R.; Schoepf, J.; Hristovski, K.; Herckes, P.; Westerhoff, P. Prospecting nanomaterials in aqueous environments by cloudpoint extraction coupled with transmission electron microscopy. Science of the Total Environment, v. 584-585, p. 515-522, 2017b. https://doi.org/10.1016/i.scitotenv.2017.01.059

Yi-Jun, Y.; Guan-Yong, S.; Lam, M. H. W.; Lam, P. K. S.; Hong-Xia, Y. Cloud point extraction of bisphenol A from water utilizing cationic surfactant Aliquat 336. Chinese Journal of Analytical Chemistry, v. 37, p. 1717-1721, 2009. https://doi.org/10.1016/S1872-2040(08)60148-6

Zana, R.; Weill, C. Effect of temperature on the aggregation behavior of nonionic surfactants in aqueous solutions. Journal de Physique, v. 46, p. 953-960, 1985. 